Int. J. Electrochem. Sci., 11 (2016) $9666-9675$

International Journal of

ELECTROCHEMICAL

SCIENCE

www.electrochemsci.org

\title{
Influence of Multi-Pass Welding on the Microstructure Evolution and Corrosion Resistance of a Super Duplex Stainless Steel
}

Yangting Sun, Xiayu Wu, Xuan Wu, Jin Li, Yiming Jiang*

Department of Materials Science, Fudan University, Shanghai 200433, China

"E-mail: corrosion@ @udan.edu.cn

doi: $10.20964 / 2016.11 .28$

Received: 8 August 2016 / Accepted: 5 September 2016 / Published: 10 October 2016

Different thermal simulations of multi-pass welding were performed on the 2507 duplex stainless steel. The influence of thermal cycles on microstructure and phase ratio was studied. The toughness and pitting resistance of different specimens were investigated through impact energy test and critical pitting temperature test, respectively. The results revealed that the microstructure and performance of 2507 were deteriorated significantly after single-pass welding. While welding pass increased, the restoration effect was observed.

Keywords: Duplex stainless steel; Multi-pass welding; Heat-affected zone; corrosion

\section{FULL TEXT}

(C) 2016 The Authors. Published by ESG (www.electrochemsci.org). This article is an open access article distributed under the terms and conditions of the Creative Commons Attribution license (http://creativecommons.org/licenses/by/4.0/). 